\title{
Injury and immune response: applying the danger theory to mosquitoes
}

\author{
Miguel Moreno-García ${ }^{1+}{ }^{\text {, Benito Recio-Tótoro }}{ }^{1,2}$, Fabiola Claudio-Piedras ${ }^{1,3}$ and \\ Humberto Lanz-Mendoza ${ }^{1}$ * \\ ${ }^{1}$ Centro de Investigaciones Sobre Enfermedades Infecciosas, Instituto Nacional de Salud Pública, Cuernavaca, México \\ 2 Instituto de Biotecnología, Posgrado en Ciencias Bioquímicas, Universidad Nacional Autónoma de México, Cuernavaca, México \\ ${ }^{3}$ Facultad de Medicina, Posgrado en Ciencias Biológicas, Universidad Nacional Autónoma de México, México City, México
}

\section{Edited by:}

Martin Heil, Centro de Investigación y de Estudios Avanzados del Instituto

Politécnico Nacional - Unidad

Irapuato, Mexico

\section{Reviewed by:}

Ulrich Theopold, Stockholm University, Sweden

Dale Ronald Walters, Scottish

Agricultural College, Scotland

\section{*Correspondence:}

Humberto Lanz-Mendoza, Centro de Investigaciones Sobre Enfermedades Infecciosas, Instituto Nacional de Salud Pública, Avenida Universidad 655, Santa María Ahuacatitlán, 62100 Cuernavaca, Morelos, México e-mail: humberto@insp.mx

${ }^{\dagger}$ Present address:

Miguel Moreno-García, Department of Microbiology, Immunology and Pathology, Colorado State University, Fort Collins, CO 80523-1690, USA
The insect immune response can be activated by the recognition of both non-self and molecular by-products of tissue damage. Since pathogens and tissue damage usually arise at the same time during infection, the specific mechanisms of the immune response to microorganisms, and to tissue damage have not been unraveled. Consequently, some aspects of damage caused by microorganisms in vector-borne arthropods have been neglected. We herein reassess the Anopheles-Plasmodium interaction, incorporating Matzinger's danger/damage hypothesis and George Salt's injury assumptions. The invasive forms of the parasite cross the peritrophic matrix and midgut epithelia to reach the basal lamina and differentiate into an oocyst. The sporozoites produced in the oocyst are released into the hemolymph, and from there enter the salivary gland. During parasite development, wounds to midgut tissue and the basement membrane are produced. We describe the response of the different compartments where the parasite interacts with the mosquito. In the midgut, the response includes the expression of antimicrobial peptides, production of reactive oxygen species, and possible activation of midgut regenerative cells. In the basal membrane, wound repair mainly involves the production of molecules and the recruitment of hemocytes. We discuss the susceptibility to damage in tissues, and how the place and degree of damage may influence the differential response and the expression of damage associated molecular patterns (DAMPs). Knowledge about damage caused by parasites may lead to a deeper understanding of the relevance of tissue damage and the immune response it generates, as well as the origins and progression of infection in this insect-parasite interaction.

\section{Keywords: danger/damage, immune response, insects, mosquitoes, wound}

\section{INTRODUCTION}

In the last 30 years research into insect immunity has blossomed, providing overwhelming evidence of the ecological costs of the immune response. It is now known that insect immunity is intimately involved in the evolution of diverse survival and reproductive strategies and correlated traits (immunity vs. developmental rates, egg production, coloring, etc.). There has also been rapid progress in unraveling the mechanisms of insect immune responses and their effects on pathogens. The distinction between self and non-self, between endogenous and exogenous, which is a fundamental aspect of vertebrate immunity, also seems to be pivotal for insect immunity (Klein, 1999). Insects, like vertebrates, are in contact with many microorganisms. Whereas some of these interactions do not have a detrimental effect on the host, others do. Hence, the concept of pathogen-associated molecular patterns (PAMPs), proposed by (Medzhitov and Janeway, 2002), has been extended to microorganism-associated molecular patterns (MAMPs) introduced by Koropatnick et al. (2004). Aside from pathogen recognition and elimination, the insect immune system must distinguish between, and respond differently to commensal and pathogenic microorganisms. This occurs via the sensing of danger/damage molecules (DAMPs), whether endogenous or exogenous. For example, it is already known that proteases secreted from microorganisms, or anomalous proteolytic activity in the hemolymph, can induce the activation of immune pathways in insects, leading to the production of antimicrobial molecules (Chamy et al., 2008). This paired system of sensing MAMPs and associated DAMPs may constitute a primary immune regulation mechanism in insects.

Matzinger (1994) was the first to state that danger signals are required to activate an appropriate defense against pathogens, and are a product of tissue or cell damage. Based on this theory, it has been suggested that tissues or cells of insects could also release danger signals and that the level of these signals should correlate with a damage threshold upon the establishment of infection (Cooper, 2010; Lazzaro and Rolff, 2011; Moreno-García et al., 2014). The idea that insects can recognize and react against these danger/damage molecules was in part proposed 45 years ago by Salt (1970). In his seminal paper, he anticipated that microorganisms damage host tissues of insects directly or indirectly by “... releasing abnormal if not toxic substances. An insect has need, then, for protection against foreign or abnormal particles of molecular 
size." He mentioned that the defense is not only related to recognition of self or non-self, but also to damage: "Since the cells of each kind of insect react to most infections, but not to all, those cells must be able to distinguish the organisms to which they react from others which they do not molest" and called attention to the fact that the ... "defence reaction must lie principally in its effect on alien parasites, and particularly on those that endanger the life of their host."

During evolution, several molecules have arisen that have a function in sending information from one living cell to another. Salt (1970) anticipated that "... blood cells react to a negative characteristic, the absence of something; or that negative characteristic must be transformed into a positive stimulus.” He also pointed out that a non-self-entity “... would be expected to have an effect on some of those substances quite apart from any effect on cells ... If those altered plasma molecules stimulated the blood cells, they would provide the positive stimulus required." In plants and animals a number of these intracellular molecules have been reported to stimulate the immune response when appearing at high concentrations in the extracellular space (reviewed in Heil, 2012). Hence, it is now considered that the immune capacities of insects rely not only on the discrimination of self and non-self, but also on a damage threshold that triggers the host "decision" to either eliminate or co-exist with microorganisms (Moreno-García et al., 2014).

Matzinger and Kamala (2011) and Medzhitov et al. (2012) proposed that tissues have an intrinsic ability to tolerate some degree of stress, damage, or malfunction. Likewise, Salt presumed that tissues must play an essential role in immunity and wound repair: "An organism attempting to infect the body of an insect (not merely its gut) must enter the haemocoel, if only to pass through it on the way to a particular tissue. Defence against such organisms can appropriately be deployed in the haemocoel, where the infection can be overcome, if the reaction is successful, before any other tissue or organ is harmed." Finally, he implicated the sensitivity of tissues, the sensing of danger/damage molecules, and the relation of these two factors to defense: "Although these parasites ultimately cause dreadful damage, they are inserted with negligible injury; and the haemocytes are inactive against them because they are within the connective tissue covering the organ." Therefore, in accordance with the ideas of Matzinger, Medzhitov et al. and Salt, in insects there must also be injury to tissues and this could be met by a variable damage tolerance. Then, for the maintenance of the integrity/morphostasis of a tissue in this animal group (see Cunliffe, 1997; Dembic, 2000), wound repair and final host survival depend on the recognition and sensing of self/non-self molecules, as well as the damage and immune response induced.

Drosophila melanogaster has been commonly used as a model for exploring the mechanisms of insect immune defense. Likewise, vector-borne mosquitoes, by virtue of their impact on human health, have also aroused interest and increased our comprehension of the molecular and cellular interactions between insects and the various developmental stages of pathogens/parasites. Although the danger/damage concept has now been incorporated into recent reviews, some aspects of damage caused by microorganisms in vector-borne arthropods have recently been neglected.
In the Anopheles-Plasmodium interaction, as the parasite passes through various stages of development it must penetrate (with associated damage) several physical barriers to reach the hemolymph and then the salivary glands: the peritrophic matrix, the midgut epithelial cell layer, and the basement membrane (BM). Much remains unclear about this process. For example, how are parasites able to develop and escape from the mosquito immune response? Given that the lifespan of the mosquito is not much longer than 30 days (Grieco et al., 2003; Hurd et al., 2005), and that parasite development takes, depending on the species of Plasmodium, from 15 to 25 days, how is it possible that the mosquito can transmit the parasite to humans? Moreover, what is the nature of the signals that activate the immune response against this parasite and associated damage? To answer these questions, we reassess the Anopheles-Plasmodium interaction by incorporating the danger/damage hypothesis and Salt's assumptions. Knowledge about damage caused by parasites may help to understand the relevance of tissue damage, the immune response, and the origin and progression of infection in this insect-parasite interaction.

\section{THE PARASITE'S MULTIPLE DEVELOPMENTAL STAGES IN MOSQUITOES}

Plasmodium is the parasitic protozoa that causes malaria. It possesses an apicoplast (a plastid-like organelle) and an apical complex, which are present in its three invasive stages. While in the vertebrate host the parasite is mainly intracellular, in the mosquito it is primarily extracellular, invading cells solely because of its need to cross tissue epithelia (Bannister and Sherman, 2009). After a mosquito ingests Plasmodium parasites (through infected blood meal), the arrested gametocytes mature and emerge from the erythrocytes within minutes. Motile microgametes fertilize macrogametes, and a zygote is formed. After 18-20 h the zygote differentiates into a motile invading stage called the ookinete, which migrates out of the blood bolus and crosses two barriers. The first one is the chitinous peritrophic matrix that is secreted by the midgut epithelial cells after each blood meal. The second is the midgut epithelium, a single cell layer surrounded by a thin and sparsely reticulated muscular tissue and the BM (Vlachou etal., 2006; Angrisano et al., 2012). The BM, an extracellular protein sheet surrounding tissues of animals, is composed primarily of laminin, collagen IV, and proteoglycans. There is a high homology in composition and function between the BM of invertebrates and vertebrates (Yurchenco and O'Rear, 1993).

Once the ookinete reaches the BM (at 24-36 h post-feeding) it ceases its mobility, fuses with this membrane, and differentiates into a vegetative oocyst. The oocyst feeds on hemolymph components to grow from about $5 \mu \mathrm{m}$ to as much as $50 \mu \mathrm{m}$ in diameter during the following 12 days. The DNA of oocysts replicates from 8 to 10 times, forming 1000s of sporozoites (Canning and Sinden, 1973; Rosenberg and Rungsiwongse, 1991; Nacer et al., 2008) that are released into the hemolymph. These sporozoites migrate, either by gliding motility while adhered to the BM or more commonly by means of the open circulatory flow. In the latter case they pass through the tubular heart to reach the salivary glands. The sporozoite then 


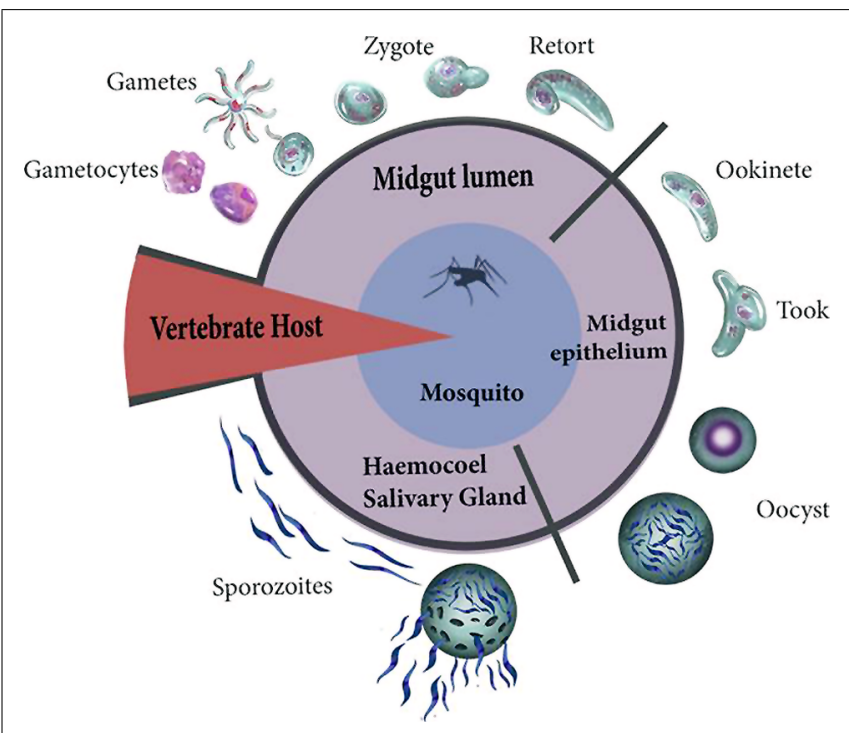

FIGURE 1 | Plasmodium invasion starts with the entry of gametocytes and formation of male and female gametes. The pronuclei of both gametes fuse for fertilization resulting in the formation of the zygote. The zygote then initiates its transformation (retort) into an ookinete. During invasion, the ookinete crosses the peritrophic matrix and reaches the luminal face of the epithelium. The ookinete differentiates (took forms) into a rapidly growing sporozoite-producing oocyst. The DNA of oocysts replicates forming 1000 s of sporozoites that are released into the hemolymph. These sporozoites migrate to reach the salivary glands.

crosses the BM and the salivary gland epithelial cells, staying in the lumen of this gland until the mosquito injects them with saliva when taking a blood meal (Rodriguez and Hernández-Hernández, 2004; Mueller et al., 2010). Maier et al. (1987) established five stages in the interaction of the malaria parasite with the host that could generate damage (Figure 1): (1) exflagellation and ookinete development; (2) epithelial damage caused by the penetration of ookinetes; (3) competition for host metabolic products by the growing oocyst; (4) sporozoite migration; and (5) penetration of salivary gland cells by sporozoites.

\section{THE MALARIA PARASITE TRANSITION IN MOSOUITOES, THE DAMAGE IT GENERATES, AND ITS ADAPTATIONS TO AVOID IT \\ OOKINETE MIDGUT INVASION}

The midgut plays a significant role in fluid and nutrient digestion and excretion, as well as in the synthesis and secretion of mucus, digestive enzymes, and the peritrophic matrix (Gooding, 1973; Hecker, 1977; Billingsley and Lehane, 1996). The latter tissue has direct contact with a wide variety of external stimuli such as the microbiota, the complex mix of dietary components, microorganisms that are ingested with the meal, by-products of digestion, pathogens, and toxins. This tissue establishes a selective barrier that actively absorbs nutrients to convert them into metabolites and store them, and provides a first line of defense against potentially harmful agents or pathogens (Gooding, 1973; Billingsley and Rudin, 1992). On the other hand, the continuity of the gut epithelium depends on the constant communication as well as the mechanical connections between its cells. These two factors establish a metabolic and electrical integration with impact on tissue homeostasis (Harvey and Blankemeyer, 1975).

During invasion, the ookinete crosses the peritrophic matrix and reaches the luminal face of the epithelium. It must subsequently adhere to these epithelial cells and invade them. Until recently there was an ongoing debate about whether the parasite takes an intracellular or intercellular route across the midgut epithelium. Those arguing in favor of an intercellular route presented evidence that the parasite was observed between the basolateral membranes of the epithelial cells. This occurs when the ookinete enters the epithelium in the regions where three epithelial cells join. However, it is now almost certain that the ookinete enters the epithelial cell, but without the formation of a parasitophorous vacuole, aided by perforin-like molecules (Angrisano et al., 2012). Ookinetes invade many cells on their way to the BM (although it is not clear why this happens), causing every invaded cell to enter into apoptosis (Han et al., 2000; Zieler and Dvorak, 2000; Vlachou et al., 2004).

It has been proposed that the apoptosis of cells and their consequent extrusion from the epithelium obliges ookinetes to migrate laterally to a neighboring cell to avoid being extruded. This idea is the so-called "time bomb" theory proposed by Han et al. (2000). Another model, denominated the "cellular treadmill" and proposed by Baton and Ranford-Cartwright (2005), suggests that ookinetes only move from the apical surface to the basal membrane of the epithelial cell, not laterally. But since neighboring cells fill the gap left behind by an apoptotic cell, an ookinete must invade these cells as well (Baton and Ranford-Cartwright, 2005).

Parasite invasion is a density-dependent process. Within a certain threshold, the lower the parasite burdens in the mosquito, the greater the transmissibility of the disease. For example, under laboratory conditions with the Anopheles stephensi-Plasmodium berghei model, the efficiency of producing oocysts begins to decrease when there are over 355 ookinetes per mosquito (Sinden et al., 2007). This is ascribed to the fact that the parasite damages the mosquito, and the energy is redirected to the immune response mounted against it (Tripet et al., 2008). Hence, the lesser the damage generated, the greater the overall fitness for both interacting species (Churcher et al., 2010). During the crossing of the mosquito midgut barriers, a further decrease in ookinete counts is observed. Despite the resulting low number of oocysts, each one is capable of forming 1000s of sporozoites, many of which are eliminated in the hemolymph by several factors (see Section "Sporozoite Invasion of the Hemocoel: Damage to the Basement Membrane, Tissue Protection, and Cellular Immunity").

Although the invasion process induces damage, well adapted and less virulent parasites could have a selective advantage. Whitten et al. (2006) mentioned: “... because the junctional complexes at the apical surface are rigid, and their integrity is vital to the survival of the cell, the parasite may attempt the mechanically less demanding and damaging process of intracellular penetration of the epithelial cells." Since leakage of the blood bolus into the hemolymph is probably a worse scenario than the parasite 


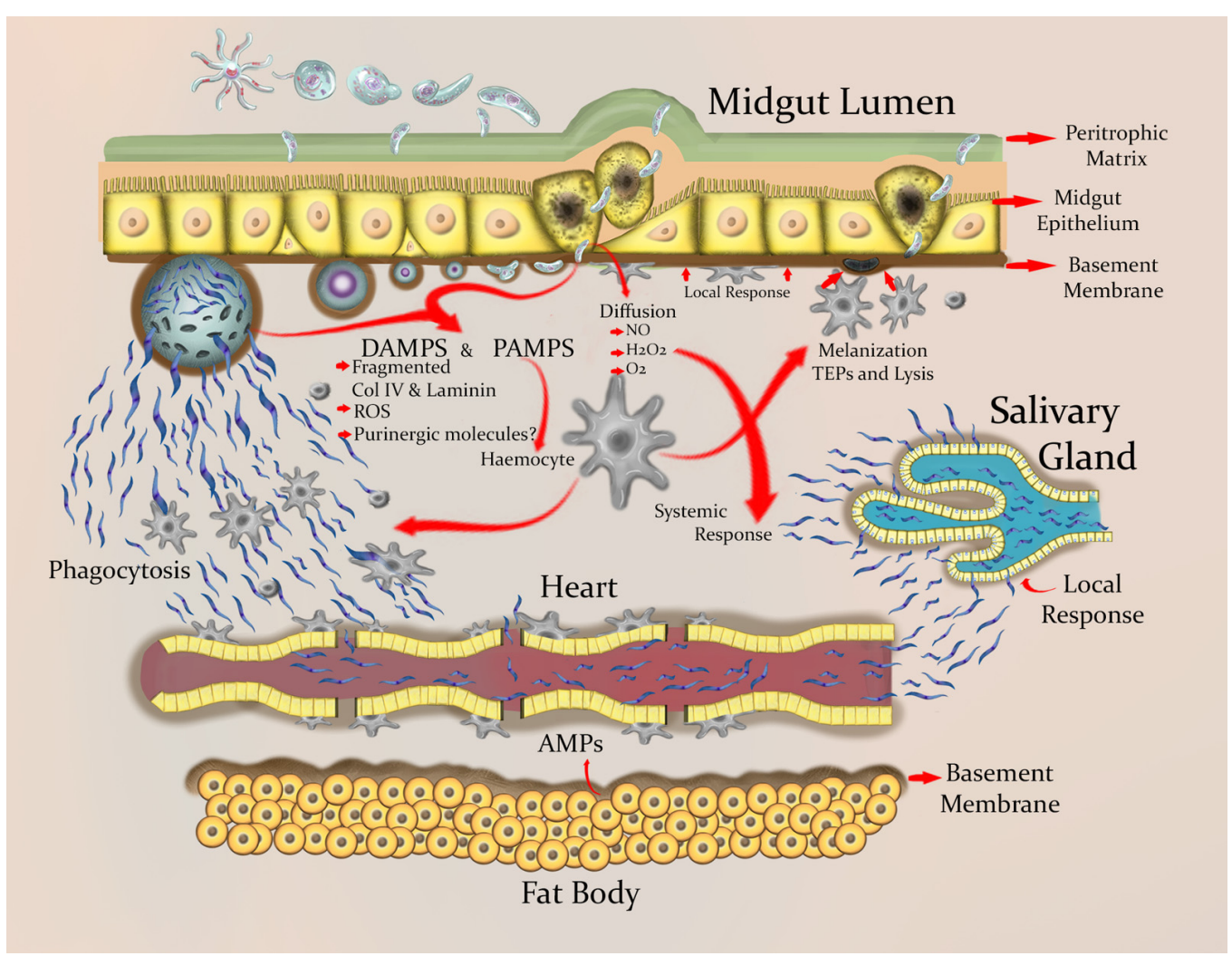

FIGURE 2 | Schematic view of the wounding and inflammation process in mosquito tissues during Plasmodium infection. Ookinetes wound the peritrophic matrix and midgut epithelial cells, which leads to the loss of some of these cells. Damaged epithelial cells are extruded, followed by the differentiation of regenerative cells and the consequent proliferative regeneration. The dead cells release intracellular contents that may function as DAMPs. ROls and adenosine-containing molecules appear to be essential endogenous signaling molecules needed for protection against danger. In Anopheles spp., genes involved in biological processes such as immune recognition, immune signaling pathways, and autophagy are expressed during a Plasmodium infection. This expression can be detected locally in the gut and systemically in body fat. ROIs limit parasite development and have signaling activity in various tissues during infection. The ookinete differentiates into an oocyst in the space between the BM and the basal side of the epithelium. In this stage the parasite is susceptible to being melanized and is exposed to TEPs, AMPs, PO cascade products, and ROls. Sporozoites emerge in the hemolymph, and are to some extent limited by the differentiation and proliferation of hemocytes. However, hemocytes have another perhaps more important function during the stage of sporozoites, which is the ability to sense small-sized BM fragments and adhere to sites where the BM is damaged and to places with cell debris. Basal lamina components for wound repair are produced by circulating hemocytes. Migration of sporozoites through the hemolymph and the tubular heart is probably hindered by the accumulation of hemocytes in the ostia. Finally, sporozoites accumulate in the salivary gland of the mosquito, from where they are transmitted to a vertebrate host. invasion itself, the ookinete may enter the cell primarily to leave the junctional complex intact (Whitten et al., 2006). Once the ookinete approaches the basal labyrinth of the epithelial cell being extruded, neighboring cells have already started to extend lamellipodia beneath the invaded cell. Thus there is no "hole" left behind by the extruded cell (Vlachou et al., 2004). Furthermore, the parasite seems to have a "hood" surrounding it, which is produced by lamellipodial extensions of the invaded cell itself. In the words of Vlachou et al. (2004): "Hood formation may be stimulated by the parasite and could represent a compromise that potentially hinders egress of the ookinete..." (at this point the ookinete is severely constrained) "... but also prevents draining of the invaded cell through the perforated plasma membrane. Draining would create a dangerous shunt between the enzyme-rich contents of the midgut lumen ..." (that is, the epithelial cell contents that spill as a result of necrosis) "... and the open circulatory system of the mosquito, the haemolymph, just across the porous basal lamina."
Ookinete invasion damages midgut epithelial cells and thus leads to cell death (Maier et al., 1987; Figure 2). However, this damage does not always have a detrimental effect on mosquito survival (Ferguson and Read, 2002). This suggests that adult female mosquitoes have an efficient mechanism for midgut repair and regeneration (Baton and Ranford-Cartwright, 2007). Following damage, epithelial cell extrusion is observed (Baton and Ranford-Cartwright, 2004) and regenerative cells differentiate into columnar cells, leading to regeneration of the mosquito midgut epithelium (Baton and Ranford-Cartwright, 2007). Interestingly, the plasma membrane of invaded epithelial cells seems compromised, and therefore intracellular contents are released (Zieler and Dvorak, 2000), The molecules of the intracellular contents, such as intracellular nucleotides, reactive oxygen species, extracellular purinergic molecules, nucleic acids, and heat shock proteins, could act as DAMPs, which when sensed by the innate immune system trigger an inflammatory response 
(Figure 2; see Section “ Is There Damage-Related Pathology and Inflammation in Plasmodium Infected Mosquitoes?"). Oxidative stress, bacterial infection, DNA damage, aging, and other factors cause apoptosis and damage to the enterocytes (Ayyaz and Jasper, 2013). However, these stressors also induce regenerative cell proliferation in the gut (Ayyaz and Jasper, 2013).

\section{THE MOSQUITO IMMUNE RESPONSE TO Plasmodium}

Insects lack an adaptive immune response based on somatic generation and clonal expansion of specific immune cells (Du Pasquier and Flajnik, 1999). However, evidence shows that insects are indeed able to enhance immunity to an infection after a first exposure (providing resistance, better immunocompetence, and survival advantages), an advantage that can persist across generations (Little et al., 2003; Little and Kraaijeveld, 2004; Kurtz, 2005; Moret, 2006; Pham and Schneider, 2008; Rodrigues et al., 2010; Tidbury et al., 2011; Contreras-Garduño et al., 2014). This mechanism is known as immune priming and is considered to be similar to vertebrate adaptive immunity (Little et al., 2005; Litman and Cooper, 2007).

In insects, both cellular and humoral components of the immune response contribute very significantly to resistance against microbial infection (Hoffmann et al., 1999). The insect immune system consists of a variety of responses, the first occurring in the epithelial barriers (epidermis, intestinal, and tracheal network). From these organs, the response may spread systemically via the hemolymph, an open circulatory system that fills the hemocoel. A systemic response primarily involves fat body (the main producer of the hemolymph proteins) and hemocytes (involved in phagocytosis, nodule formation, and encapsulation). These humoral and cellular components allow for a rapid and efficient insect immune response upon infection.

Overall, the defense processes of insects can be divided into two main stages: recognition and response. Each of these are connected by signaling pathways and regulated by modulating elements (Christophides et al., 2004). Molecules involved in recognition have been grouped as soluble receptors and those located in cell membranes. Recognition is carried out by proteins that recognize peptidoglycan and Gram-negative bacteria, thioester bond-containing proteins (TEPs), and scavenger receptor type lectins. After the foreign element is recognized, a signal is transmitted to the cell nucleus for activation of target genes. These pathways include the Toll and IMD systems, and in the case of mosquitoes a third one named the JAK/STAT pathway. Modulation of the response is mediated by extracellular serine protease cascades, which are regulated by specific inhibitors (serpins). Defense responses include the activation of a large number of genes, and characteristic effectors include antimicrobial peptides (AMPs), melanization dependent on the phenoloxidase (PO) cascade, and apoptosis-related genes (Figure 2). Regarding the immune response to intracellular infectious agents such as viruses, it is speculated that the Toll and JAK/STAT pathways are involved (Sanders etal., 2005; Rivkin etal., 2006), but the underlying signaling mechanism is still unknown.
When Anopheles gambiae is challenged with different pathogens or infected with Plasmodium parasites, at least 200 genes are differentially expressed (Dimopoulos et al., 2002). The expression of immune markers during Plasmodium infection can be detected locally in the gut and systemically in body fat. The latter is considered the main tissue that produces immune proteins released into the hemolymph (Dimopoulos et al., 1998, 2002). Overexpression of immune genes during infection begins when parasites are present in the mosquito midgut (Luckhart et al., 2003). Recently, Martinez-Barnetche et al. (2012), explored different tissues of the adult female of An. albimanus to identify the transcriptome related to a Plasmodium infection. They identified protein-coding transcripts involved in biological processes such as immunerecognition, immune signaling pathways, insecticide resistance, and autophagy, all of which are related to a Plasmodium infection. The analysis of the midgut of An. albimanus infected with $P$. berghei revealed the proteins that are differentially expressed during this immune challenge (Serrano-Pinto et al., 2010). The two most common functional classes are immunity/defense $(34.78 \%)$ and blood digestion proteases (15.21\%).

There is evidence that the production of nitric oxide (NO) in the midgut epithelium of the mosquito An. stephensi limits the development of P. berghei (Luckhart et al., 1998; Han et al., 2000; Luckhart and Li, 2001). The midgut of An. pseudopunctipennis responds similarly by producing $\mathrm{NO}$ in the presence of bacteria, yeasts and Plasmodium (Herrera-Ortíz et al., 2004), while that of An albimanus produces reactive oxygen species (e.g., the superoxide anion) that are toxic to P. berghei ookinetes (Lanz-Mendoza etal., 2002). These observations suggest the importance of various tissues during the immune response of these mosquitoes.

It is possible that the immunological response mounted by a mosquito during an ookinete invasion is not the only mechanism limiting the density of parasites. The malaria parasite itself might contribute to the regulation of its density in mosquitoes by means of programmed cell death (PCD; Pollitt et al., 2010; Matthews et al., 2012). This possibility together with the apoptosis of midgut cells that are invaded by ookinetes (Zieler and Dvorak, 2000), which are extruded from the epithelium into the lumen of the midgut (Han et al., 2000), suggests a certain limit for the number of ookinetes than can pass through the midgut before the physiology of the intestinal tissue is compromised. Therefore, the parasite might develop the counterintuitive strategy (in terms of intraspecific competition, but not in terms of evolutionary ecology) of regulating its population density in order to minimize the damage to the host. This behavior has been observed in the blood stages (Mutai and Waitumbi, 2010) and the mosquito stages of the parasite (Al-Olayan et al., 2002), although the latter needs to be considered critically since the ookinetes are not clones, because they are produced after sexual reproduction. If this hypothesis holds, it will emphasize the importance for the parasite of avoiding an overactive immune response of its host to avoid damage to the latter.

\section{THE MALARIA PARASITE INVISIBILITY CLOAKS}

Reaching the BM is only half the trajectory the malaria parasite must complete to be transmitted to the next vertebrate host. 
Between the BM and the basal side of the epithelium surrounded by the hemolymph, this parasite enters a vegetative stage of 10-15 days in which the ookinete differentiates into a rapidly growing sporozoite-producing oocyst. In this period the parasite is melanized by hemocytes (Whitten et al., 2006) and exposed to soluble immune proteins like the TEPs (Marois, 2011), antimicrobial peptides, PO metabolites, and reactive oxygen and nitrogen species (Luckhart et al., 1998; Lanz-Mendoza et al., 2002; HerreraOrtíz et al., 2004; Herrera-Ortiz et al., 2011; Clayton et al., 2014). Nevertheless, there is evidence of strategies employed by the parasite to render itself invisible to the immune response. Arrighi et al. (2005) have shown than the ookinetes, as well as the oocyst, are coated with laminin derived from the mosquito. Furthermore, when these researchers silenced the laminin gene with dsRNA, the transmission of the parasite was hampered (Arrighi etal., 2005). A related study found that Sephadex molecules covered with laminin derived from mice, Drosophila cells, or the parasite surface protein PgS28 (which binds laminin) were less melanized in comparison with non-coated Sephadex beads when inoculated into the hemocoel of Aedes aegypti (Warburg et al., 2007). However, these experiments do not provide definitive proof for this "mask theory" because parasite development may have been hampered for reasons other than a masking mechanism.

Interestingly, Nacer et al. (2008) found laminin to be present not only in the oocyst capsule but also in the membrane of the developing sporozoites within the oocysts. This suggests that the oocyst covers the sporozoites with laminin during their formation to prevent their melanization upon release to the hemocoel. The finding that the oocyst has transglutaminase, which could crosslink mosquito proteins - including laminin - to the capsule (Nacer et al., 2008; Smith and Jacobs-Lorena, 2010), suggests that the components of the oocyst capsule may be derived from parasite and mosquito proteins. However, this question requires further research.

Finally, there is recent evidence that PSF47, a surface ookinete protein, somehow inhibits the expression of the epithelial heme peroxidase (HPX2) and NADPH oxidase 5 (NOX5). The expression of these two proteins leads to the nitration of ookinete surface proteins, which could cause the parasite to be tagged for TEP1 mediated lysis or melanization when reaching the BM. However, this applies to some parasite-mosquito species (or strains) reflecting a local arm race between the parasite and the mosquito (Molina-Cruz et al., 2013; Philip and Waters, 2013).

\section{SPOROZOITE INVASION OF THE HEMOCOEL: DAMAGE TO THE BASEMENT MEMBRANE, TISSUE PROTECTION AND CELLULAR IMMUNITY}

Once the oocyst is completely mature, sporozoites emerge in the hemolymph and invade the salivary gland. Sporozoites accumulate in the salivary ducts of the glands and from there are transmitted to a mammalian host. From 1000s of sporozoites released, only $10-25 \%$ manage to invade the salivary glands (Sinden and Billingsley, 2001). What are the mechanisms that could explain this drastic reduction in sporozoites? Some authors have suggested a possible interaction between cellular and humoral molecules (e.g., Pinto et al., 2008), such as AMPs, complement-like proteins and molecules produced during the melanization process (PO cascade; e.g., Dimopoulos et al., 2002; Clayton et al., 2014).

Hemocytes are strongly activated during the ookinete and oocyst stages, and the cellular response is responsible for conferring immune memory against the latter stage (Rodrigues et al., 2010; Ramirez et al., 2014). Hemocytes count increase and also are induced to differentiate during the sporozoite stage as well (Hillyer et al., 2007), and are partly responsible for limiting sporozoite circulation in the hemocoel (Hillyer et al., 2003). However, phagocytosis and melanotic encapsulation is weak (HernándezMartínez et al., 2002). Even some TEPs, which are produced by the hemocytes and efficiently bind to and mediate the killing of ookinetes and oocysts, do not bind to sporozoites (Blandin et al., 2004). Why do the morphology and number of hemocytes change during the sporozoite stage if this immune molecule responds only weakly against sporozoites? There are two possible and related explanations: (1) the cellular response becomes activated mainly for BM wound repair, and (2) the immune response is aimed to protect tissues (e.g., heart) with a lower intrinsic ability to tolerate damage.

Sinden (1974) reported the presence of small holes (0.25-0.65 $\mu \mathrm{m}$ in diameter) in the oocyst that were limited to areas of about $15 \mu \mathrm{m}$. For sporozoites to be released from the oocyst wall, the BM must be ruptured or degraded (or at least some continuity must be lost), however, the partially disrupted BM did not prevent sporozoites from being released (Sinden, 1974; Sinden and Strong, 1978; Meis et al., 1992). Since the BM separates midgut epithelial cells from the hemolymph and hemocoel, damage to this tissue must heal quickly. Then, immediately after sporozoite invasion into the hemolymph, BM wound healing must sets in to isolate the hemocoel and prevent intrusion of opportunistic bacterial via co-penetration.

Lackie (1988) proposed that an important role of hemocytes is the formation and repair of the BM and wound sealing, where the numbers and subpopulations of hemocytes vary in response to the extent of damage and introduction of foreign material. She (like Salt) pointed out that the immune system discriminates degrees of difference from self, a task that requires soluble factors derived from the wounded area. These factors control the resulting hemocytic response (Lackie, 1988). In Drosophila, sterile damage in cuticular basal lamina (which is part of the BM) promotes hemocyte differentiation and an increment in hemocyte counts (Márkus et al., 2005). Related to this idea of a damage-induced immune response, Nayar and Knight (1995), showed that cuticle wounding (with an injection of saline solution) enhanced the cellular encapsulation and melanization responses against a nematode. Moreover, hemocytes adhere to sites where the BM is damaged, but not to an intact BM (Rizki and Rizki, 1980). Meanwhile, circulating hemocytes are rapidly recruited to the site of damage. The first arriving hemocytes bind to sites where cell debris exist (Babcock et al., 2008). In An. gambiae basal lamina components are produced by circulating hemocytes, which secrete them onto cell surfaces within the hemocoel (Pastor-Pareja et al., 2008). Thus, it is likely that degraded components of the BM serve as DAMPs (Figure 2).

In agreement with this idea, Altincicek and co-workers (Altincicek and Vilcinskas, 2006; Altincicek et al., 2007) have 
proved the ability of the insect to sense small-sized collagen IV fragments. These fragments induce the activation Toll and IMD immune pathways (in body fat), leading to the synthesis of antimicrobial molecules (Altincicek and Vilcinskas, 2006). In Anopheles mosquitoes, the anti- Plasmodium defense is principally controlled by these two pathways (Clayton et al., 2014). Therefore, during sporozoite release and invasion, it is possible that the BM is damaged and that the recognition of free fragments induces hemocyte recruitment. On the other hand, the increased number of circulating hemocytes could be more a consequence of the activation of immune pathways related to the sensing of the parasite and DAMPs (Pastor-Pareja et al., 2008).

The fact that in mosquitoes the cellular response is activated against ookinetes and oocysts, and that this elicits an enhanced immune response when re-exposed (immune priming), could be related with the capacity of the immune system to adjust its primary response after exposure to danger signals ("memory of danger," sensu Noble, 2009). Foley (1978) suggested that if hemocytes respond to a BM disruption, their adherence to the $\mathrm{BM}$ leaves fewer circulating hemocytes to respond to the migrating sporozoites. In mosquitoes, immune priming has been supported by experimental approaches (Rodrigues et al., 2010; ContrerasGarduño et al., 2014; Ramirez et al., 2014). Thus, danger signals may induce immune responses that protect the injured tissue from opportunistic infections. Tissues have an intrinsic ability to tolerate some degree of stress, damage, or malfunction. Therefore, the cellular response elicited during midgut invasion and oocyst establishment implies communication between the midgut epithelium, hemocytes and other tissues that have not yet had direct interaction with the pathogens (see Section "Danger Molecules"). Subsequently, if pathogens get access to the hemocoel and tissues therein, an enhanced primed response may limit damage in these tissues.

In An. gambiae, sessile hemocytes exist in a relatively high proportion $(\sim 25 \%)$. They have an efficient phagocytic activity and are mainly attached to the trachea or the ostia of the heart, which could function as a protective strategy to limit potential pathogen dispersal through hemocoel (King and Hillyer, 2013). In insects, the circulatory system consists of a dorsal vessel that allows for the transport of hormones, waste materials and nutrients, as well as immune surveillance by the circulation of molecules and hemocytes (Klowden, 2008). When mosquitoes become infested with sporozoites, there is an induction of phagocytic hemocyte aggregation in the dorsal vessel (pericardial region; King and Hillyer, 2012). Hemocyte recruitment and attachment along the dorsal vessel and pericardial cells (nephrocytes; see Hernández-Martínez et al., 2013) may serve as an efficient strategy for eradicating some sporozoites, but perhaps more importantly for limiting the entrance of other pathogens through a wound in the BM (e.g., Matuschewski, 2006) and protect and maintain tissue integrity.

Injury to the BM and the probability of further damage to other tissues could be considered an activator of the immune response, which would represent evolutionary changes similar to those found with immune responses against pathogens in insects. The initial molecular factors (and/or mediators) of damage responses use the same immune cells and pathways as the immune response to invasive parasites, and could stimulate unique types of reactions when damage/danger and parasites are sensed at the same time (e.g., Chamy et al., 2008). If this dual system does in fact exist, the activation of the immune response not only depends on the type of pathogen, but also on the presence, intensity, and probability of damage.

\section{DANGER MOLECULES REACTIVE OXYGEN INTERMEDIATES (ROI)}

Medzhitov et al. (2012) suggested that tissues differ in their ability to tolerate stress and damage. The communication among tissues could be useful if some tissues have low or no renewal capacity. Therefore, the response observed during early Plasmodium development suggests the interaction of molecules of the midgut epithelium with other cells and tissues that have not yet had direct contact with the parasite, thus mediating a systemic immune response to wound prevention.

Inducible DAMPs released by metabolically stressed cells are reactive oxygen intermediates (ROS), and these molecules have been found to activate NF- $\kappa \mathrm{B}$ in flies and mammalian cells (Gallucci and Matzinger, 2001). In mammals, the effects of reactive oxygen intermediates (ROIs) have been reported in several aspects of innate and adaptive immune responses (Rutault et al., 1999). Hence, endogenous factors influence the maturation of immune cells (Bagley et al., 2006). In insects the role of free radicals in the elimination of pathogens is well known, but their possible function as damage signals for activating the immune response is not as well understood. Recently it has been documented that the systemic wound response (SWR) in Drosophila is dependent on a serine protease called Hayan (Nam et al., 2012). This protease is able to sense integumental wounds and activates the phenoloxydase cascade (PPO). It is also known that during the activation of the PPO cascade several ROS are produced (Nappi and Vass, 1993), including hydrogen peroxide $\left(\mathrm{H}_{2} \mathrm{O}_{2}\right)$. The latter molecule leads to the activation of JNK-dependent cytoprotecive program in neuronal tissues (Nam et al., 2012). As can be appreciated, these findings provide a link between wound response and the nervous system.

In An. gambiae, $\mathrm{H}_{2} \mathrm{O}_{2}$ levels increase dramatically after a blood meal, probably due to an increase in the metabolic processes associated with blood digestion and oogenesis (DeJong et al., 2007), as well as the defense mechanisms induced by bacterial growth in the midgut after blood-feeding. On the other hand, it has been suggested that $\mathrm{H}_{2} \mathrm{O}_{2}$ contributes to mosquito defenses. Levels of $\mathrm{H}_{2} \mathrm{O}_{2}$ significantly increase in an An. gambiae malaria refractory strain (compared to the susceptible strain) after an infected blood meal (Kumar et al., 2003). Also, in the presence of L-DOPA, the hemolymph and midgut of anopheline mosquitoes generate the superoxide anion, which is toxic to P. berghei ookinetes (LanzMendoza et al., 2002; Kumar and Barillas-Mury, 2005). NO is produced in the Anopheles midgut during a Plasmodium infection (Dimopoulos et al., 1998; Luckhart et al., 1998; Herrera-Ortíz et al., 2004), and this molecule and its metabolites limit parasite development (Luckhart et al., 1998; Peterson et al., 2007). In Drosophila, infection with Gram-negative bacteria induces the expression of nitric oxide synthase (NOS). The inhibition of NOS diminishes larval survival in the face of Gram-negative bacterial 
infection. In An. Gambiae, midgut epithelial cells also respond to Plasmodium ookinete invasion by inducing the expression heme peroxidase 2 (HPX2), which in combination with NOS mediates parasite nitration (Kumar et al., 2004; Oliveira et al., 2012).

The involvement of $\mathrm{H}_{2} \mathrm{O}_{2}$ in the activation of the acute phase of the immune response via NF- $\kappa \mathrm{B}$ is well documented (Gloire et al., 2006). In Hyalophora cecropia, the immunoresponsive factor (CIF) could be activated by $\mathrm{H}_{2} \mathrm{O}_{2}$ (Sun and Faye, 1995), and 5$S$-GAD (N- $\beta$-alanyl-5-S-glutathionyl-3,4-hydroxyphenylalanine) from Sarcophaga peregrina produces $\mathrm{H}_{2} \mathrm{O}_{2}$ and is an activator of NF-кB (Natori, 1998). Additionally, NO produced during infection is involved in signal transduction for the expression of immune response genes. On the other hand, the inhibition of NOS activity prevents the induction of diptericin (Nappi et al., 2000; Foley and O'Farrell, 2003). Exogenous NO induced the production of this AMP in uninfected Drosophila larvae (Foley and O'Farrell, 2003), and the injection of an NO donor induced the expression of the cecropin B gene in Bombyx mori (Imamura et al., 2002).

It has been reported that the expression of AMPs is induced by the exogenous addition of $\mathrm{NO}$ and $\mathrm{H}_{2} \mathrm{O}_{2}$ in the midgut and abdominal tissue in An. albimanus infected with the rodent malaria parasite $P$. berghei (Herrera-Ortiz et al., 2011). This observation indicates that $\mathrm{NO}$ and $\mathrm{H}_{2} \mathrm{O}_{2}$, produced in the mosquito midgut during infection, might function as signals for the activation of the mosquito systemic immune response. On the other hand, midgut infection induced an increase in the expression of the three AMPs in both the midgut and abdominal tissue, while $\mathrm{NO}$ and $\mathrm{H}_{2} \mathrm{O}_{2}$ were present in the hemolymph. The induction of AMPs in abdominal tissues during midgut infection indicates communication between the midgut cells and abdominal tissue that has not yet had direct contact with the parasites. NO and $\mathrm{H}_{2} \mathrm{O}_{2}$ are an important part of this communication.

NOS induction may also occur through the generation of ROI. The upstream sequence of the NOS gene from An. stephensi has putative inflammatory responsive elements, including NF- $\kappa \mathrm{B}$ (Luckhart and Rosenberg, 1999), and several lines of evidence indicate that $\mathrm{ROI}$, in particular $\mathrm{H}_{2} \mathrm{O}_{2}$, are secondary messengers or activators of NF- $\kappa$ B (Nappi et al., 1995; Nappi and Vass, 1998; Mercurio and Manning, 1999). L-DOPA has been reported to induce ApNOS, but this induction could be aborted by catalase, indicating the participation of $\mathrm{H}_{2} \mathrm{O}_{2}$ in the process. Although no direct measure of $\mathrm{H}_{2} \mathrm{O}_{2}$ was made during the induction of ApNOS with different microorganisms, it has been observed that the midgut of An. albimanus mosquitoes, when inoculated by enema with $P$. berghei ookinetes, produced higher ${ }^{-} \mathrm{O}_{2}$ than the midgut of mosquitoes inoculated with RPMI (Lanz-Mendoza, unpublished results). These observations indicate that malaria parasites may elicit ROI production in the cells of the midgut. Host DAMPs are released during stress and this triggers inflammation, which implies a potential danger to the host. ROI molecules could function as damage signals that activate the mosquito systemic immune response.

\section{PURINERGIC MOLECULES}

Most living cells, tissues, and organisms have some form of sensitivity to purinergic molecules, such as ATP, AMP, ADP, and adenosine. The pervasive presence and abundance of all these molecules required their recruitment for intercellular signaling. ATP has an essential role in the mediation of pain, the activation of immune cells, the communication among nerve cells, and, importantly, the activation of the immune response (Trautmann, 2009; Burnstock and Verkhratsky, 2012). It is known that ATP-mediated signaling is used as a proxy for cell damage and the release of the intracellular content (e.g., Cook and McCleskey, 2002; Ivison et al., 2011; Zeiser et al., 2011).

Insects use purinergic molecules as phagostimulants (Friend and Smith, 1977) for energy metabolism and neuronal activity (Burnstock and Verkhratsky, 2009). In Manduca sexta, hemocytes hydrolyze extracellular ATP, and this activity increases when bacterial lipopolysaccharide is present (Meyer-Fernandes et al., 2000). Intriguingly, while ATP receptors (P2X) have been reported for some invertebrate groups, vertebrates and plants, non-homologous receptors have been found in insects (Fountain and Burnstock, 2009). The purinoreceptors in insects are adenosine receptors (AdoRs), and these respond to adenosine but not ATP (Trautmann, 2009). In this sense insect AdoRs are divergent from the mammalian AdoRs, but they both share the region for adenosine binding (Dolezelova et al., 2007).

Adenosine is a component of adenine nucleotides and can be generated through the release and degradation of ATP by adenosine deaminase (ADA), or by RNA degradation following cell death (Hirschhorn and Candotti, 2007). In vertebrates, extracellular adenosine has been proposed as an immediate sign of tissue damage (reviewed in Sitkovsky and Ohta, 2005). In insects, the role for adenosine has been suggested as a local paracrine and autocrine homeostatic regulator, indicating an evolutionarily well-conserved homeostatic mechanism (Dolezelova et al., 2007). In Drosophila, different cell types respond to extracellular adenosine and locally regulate its levels (Zurovec et al., 2002). Novakova and Dolezal (2011) reported that ADA expression is induced in encapsulating hemocytes, and that this can be correlated with tissue damage, the activation of Toll and JAK/STAT pathways, and the melanization of intrahemocoelic parasitic eggs (deposited by wasps into host hemocoel).

In Anopheles mosquitoes, the study of purinergic molecules and receptors is uncommon. Genes belonging to the adenosine deaminase-related growth factors (ADGF), ADA-like (ADAL), and AMP deaminase (AMPD) families have been reported for An. gambie. These families share ADA activity and an evolutionary relationship, suggesting an orchestrated control of adenosine levels (Maier et al., 2005). In mosquitoes (as well in other insect groups) it is unclear how extracellular purinergic molecules exert immune responses. Nonetheless, the occurrence of damage or death of midgut cells could lead to the release of this kind of molecule, which may activate receptors on adjacent cells. Adeninecontaining molecules appear to be essential endogenous signaling molecules in mosquitoes, providing protection against danger in these insects just as they do in plants and vertebrates.

\section{IS THERE DAMAGE-RELATED PATHOLOGY AND INFLAMMATION IN Plasmodium INFECTED MOSQUITOES?}

Ross (1902) was the first to observe the presence of "black spores" in infected mosquitoes (which correspond to parasites killed by 
encapsulation and melanization), leading to the conclusion that an infection was occurring in mosquito tissue, and that the insect responded to the parasite by encapsulating it. Pathological signs and symptoms in insects also manifest themselves as changes in coloration, abnormalities in movements and responses to stimuli, digestive disorders, and incapability to feed or reproduce (Tanada and Kaya, 1993).

Ferguson and Read (2002) concluded that in almost every case the parasite reduces the fitness of the mosquito. They described five effects in a mosquito infected with Plasmodium: (1) tissue damage and increased susceptibility to other infections, (2) a reduction in the levels of digestive enzymes, indicating a physiological change, (3) resource depletion (lower concentrations of free amino acids in the hemolymph, reflecting an increase in nutrient consumption), (4) an immune response, meaning that energy is directed to defense instead of being used for growth and reproduction, and (5) behavioral changes, such as the increased time required for feeding and the increased frequency of probing, penetration and feeding. A possible mechanism that could explain changes in feeding behavior is the decreased activity of salivary apyrase, a platelet inhibitor. Furthermore, the work of Rossignol et al. (1984) associated the decrease of salivary apyrase with the presence of fine lesions in the salivary gland (see Ferguson and Read, 2002). The virulence of Plasmodium depends on its mechanisms of invasion, which are responsible for the degree of damage done to the mosquito (Maier et al., 1987).

Historically, tissue damage has been related to redness, swelling, heat, and pain, currently known as the Celso's cardinal signs of inflammation. Virchow (1863) mentioned a fifth cardinal sign - functio laesa, or a loss of function of the damaged tissue. Histopathological studies of inflammation have almost invariably been performed on vertebrates. However, the first studies that revealed the essential components of the complex phenomenon of inflammation were done on invertebrates (Metchnikoff, 1893). Based on the Darwin-Wallace conception of natural selection, the biological theory of Pasteur and the theory of cellular pathology of Virchow, Metchnikoff (1893) suggested that real inflammation, that which has been preserved along the phylogeny, occurs without heat and redness.

As in vertebrates, inflammation in invertebrates is produced by insults or lesions to cells and tissues, leading to the release of humoral substances that promote this immune response and to the migration of cells in the serum. The effect of inflammation is wound repair, replenishment of damaged cells, and the phagocytosis of dead cells (Metchnikoff, 1893). However, some of the soluble pathogenic and molecular components in the serum do not induce inflammation directly. Rather, they are associated with the signaling pathways of receptors on a cell surface that drive the cell to self-destruction. In turn, cell death regulates inflammation by releasing cell components or derivatives that alter the function of other cells, driving them to death or survival (Wallach et al., 2014). This is relevant presently because the interaction between Plasmodium and a mosquito leads to cell death in both organisms (Hurd et al., 2006). Studies designed to comprehensively evaluate potential regulatory effects of cell death could contribute to the understanding of this complex interaction.

\section{PERSPECTIVES}

The Anopheles mosquito has become an important model for the study of how invertebrate immunity functions. Moreover, studying the development of Plasmodium in mosquitoes provides a significant opportunity to link tissue damage and the immune response. However, few studies have been conducted with molecules involved in signaling or tissue damage, molecules that may participate in activation and regulation of the immune response. Molecules involved in non-self recognition, while those that recognize damage-related molecular patterns (DAMPs) trigger signaling pathways that mobilize cellular and humoral defenses. The study of these three types of molecular patterns and their recognition will continue to involve ecologists, evolutionists, mosquito physiologists, and molecular immunologists. We encourage researchers to consider and incorporate Matzinger's danger/damage hypothesis and George Salt's injury assumptions when studying other insect-pathogen interactions. Future studies of the mechanistic attributes of damage produced during the pathogen-mosquito interaction could provide valuable information for understanding the activation and efficiency of the immune response under natural conditions.

Genomic and bioinformatics approaches have produced massive assemblages of information related to insect immunology in only a few years. We can expect that these data will provide a framework for the interpretation of the damage/immune response that could not have been inferred from studying the individual components in isolation. This kind of approach has been applied to comprehend the complex biological processes of wound healing (Aderem and Smith, 2004; Vodovotz, 2006), as well as host-pathogen interactions (Forst, 2006).

\section{ACKNOWLEDGMENTS}

Miguel Moreno-García thanks the Fogarty International Training Grant (Training in Dengue Prevention and Control) for a postdoctoral fellowship and the Fondo Sectorial de Investigación para la Educación SEP-CONACYT (Project: 183027). We thank Bruno Zarate-Garcia for image art. We thank Allan Larsen for revising this paper in English.

\section{REFERENCES}

Aderem, A., and Smith, K. D. (2004). A systems approach to dissecting immunity and inflammation. Semin. Immunol. 16, 55-67. doi: 10.1016/j.smim.2003. 10.002

Al-Olayan, E. M., Williams, G. T., and Hurd, H. (2002). Apoptosis in the malaria protozoan, Plasmodium berghei: a possible mechanism for limiting intensity of infection in the mosquito. Int. J. Parasitol. 32, 1133-1143. doi: 10.1016/S00207519(02)00087-5

Altincicek, B., Linder, M., Linder, D., Preissner, K., and Vilcinskas, A. (2007). Microbial metalloproteinases mediate sensing of invading pathogens and activate innate immune responses in the Lepidopteran model host Galleria mellonella. Infect. Immun. 75, 175-183. doi: 10.1128/IAI.01385-06

Altincicek, B., and Vilcinskas, A. (2006). Metamorphosis and collagen-IV-fragments stimulate innate immune response in the greater wax moth, Galleria mellonella. Dev. Comp. Immunol. 30, 1108-1118. doi: 10.1016/j.dci.2006.03.002

Angrisano, F., Tan, Y-H., Sturm, A., McFadden, G. I., and Baum, J. (2012). Malaria parasite colonization of the mosquito midgut: placing the plasmodium ookinete centre stage. Int. J. Parasitol. 42, 519-527. doi: 10.1016/j.ijpara.2012.02.004

Arrighi, R. B. G., Lycett, G., Mahairaki, V., Siden-Kiamos, I., and Louis, C. (2005). Laminin and the malaria parasite's journey through the mosquito midgut. J. Exp. Biol. 208, 2497-2502. doi: 10.1242/jeb.01664 
Ayyaz, A., and Jasper, H. (2013). Intestinal inflammation and stem cell homeostasis in aging Drosophila melanogaster. Front. Cell. Infect. Microbiol. 3:98. doi: 10.3389/fcimb.2013.00098

Babcock, D. T., Brock, A. R., Fish, G. S., Wang, Y., Perrin, L., Krasnow, M. A., et al. (2008). Circulating blood cells function as a surveillance system for damaged tissue in Drosophila larvae. Proc. Natl. Acad. Sci. U.S.A. 105, 10017-10022. doi: 10.1073/pnas.0709951105

Bagley, K. C., Abdelwahab, S. F., Tuskan, R. G., and Lewis, G. K. (2006). Cholera toxin indirectly activates human monocyte-derived dendritic cells in vitro through the production of soluble factors, including prostaglandin E2 and nitric oxide. Clin. Vaccine Immunol. 13, 106-115. doi: 10.1128/CVI.13.1.106-115.2006

Bannister, L. H., and Sherman, I. W. (2009). Plasmodium. eLS. doi: 10.1002/9780470015902.a0001970.pub2

Baton, L. A., and Ranford-Cartwright, L. C. (2004). Plasmodium falciparum ookinete invasion of the midgut epithelium of Anopheles stephensi is consistent with the time bomb model. Parasitology 129, 663-676. doi: 10.1017/S0031182004 005979

Baton, L. A., and Ranford-Cartwright, L. C. (2005). How do malaria ookinetes cross the mosquito midgut wall? Trends Parasitol. 21, 22-28. doi: 10.1016/j.pt.2004.11.001

Baton, L. A., and Ranford-Cartwright, L. C. (2007). Morphological evidence for proliferative regeneration of the Anopheles stephensi midgut epithelium following Plasmodium falciparum ookinete invasion. J. Invertebr. Pathol. 96, 244-254. doi: 10.1016/j.jip.2007.05.005

Billingsley, P. F., and Lehane, M. J. (1996). "Structure and ultrastructure of the insect midgut," in Biology of the Insect Midgut, eds M. J. Lehane and P. F. Billingsley (The Netherlands: Springer), 3-30.

Billingsley, P. F., and Rudin, W. (1992). The role of the mosquito peritrophic membrane in bloodmeal digestion and infectivity of Plasmodium species. J. Parasitol. 78, 430-440. doi: 10.2307/3283640

Blandin, S., Shiao, S-H., Moita, L. F., Janse, C. J., Waters, A. P., Kafatos, F. C., et al (2004). Complement-like protein TEP1 is a determinant of vectorial capacity in the malaria vector Anopheles gambiae. Cell 116, 661-670. doi: 10.1016/S00928674(04)00173-4

Burnstock, G., and Verkhratsky, A. (2009). Evolutionary origins of the purinergic signalling system. Acta Physiol. 195, 415-447. doi: 10.1111/j.17481716.2009.01957.x

Burnstock, G., and Verkhratsky, A. (2012). Purinergic Signalling and the Nervous System. Berlin: Springer. doi: 10.1007/978-3-642-28863-0

Canning, E. U., and Sinden, R. E. (1973). The organization of the ookinete and observations on nuclear division in oocysts of Plasmodium berghei. Parasitology 67, 29-40. doi: 10.1017/S0031182000046266

Chamy, L. E., Leclerc, V., Caldelari, I., and Reichhart, J-M. (2008). Sensing of 'danger signals' and pathogen-associated molecular patterns defines binary signaling pathways 'upstream' of toll. Nat. Immunol. 9, 1165-1170. doi: 10.1038/ ni. 1643

Christophides, G. K., Vlachou, D., and Kafatos, F. C. (2004). Comparative and functional genomics of the innate immune system in the malaria vector Anopheles gambiae. Immunol. Rev. 198, 127-148. doi: 10.1111/j.0105-2896.2004. 0127.x

Churcher, T., Dawes, E., Sinden, R., Christophides, G., Koella, J., and Basanez, M-G. (2010). Population biology of malaria within the mosquito: density-dependent processes and potential implications for transmission-blocking interventions. Malar. J. 9, 311. doi: 10.1186/1475-2875-9-311

Clayton, A. M., Dong, Y., and Dimopoulos, G. (2014). The Anopheles innate immune system in the defense against malaria infection. J. Innate Immun. 6, 169-181. doi: $10.1159 / 000353602$

Contreras-Garduño, J., Rodríguez, M. C., Rodríguez, M. H., Alvarado-Delgado, A., and Lanz-Mendoza, H. (2014). Cost of immune priming within generations: trade-off between infection and reproduction. Microbes Infect. 16, 261-267. doi: 10.1016/j.micinf.2013.11.010

Cook, S. P., and McCleskey, E. W. (2002). Cell damage excites nociceptors through release of cytosolic ATP. Pain 95, 41-47. doi: 10.1016/S0304-3959(01)00372-4

Cooper, E. L. (2010). Evolution of immune systems from self/not self to danger to artificial immune systems (AIS). Phys. Life Rev. 7, 55-78. doi: 10.1016/j.plrev.2009.12.001

Cunliffe, J. (1997). Morphostasis: an evolving perspective. Med. Hypotheses 49, 449-459. doi: 10.1016/S0306-9877(97)90062-1
DeJong, R. J., Miller, L. M., Molina-Cruz, A., Gupta, L., Kumar, S., and BarillasMury, C. (2007). Reactive oxygen species detoxification by catalase is a major determinant of fecundity in the mosquito Anopheles gambiae. Proc. Natl. Acad. Sci. U.S.A. 104, 2121-2126. doi: 10.1073/pnas.0608407104

Dembic, Z. (2000). Immune system protects integrity of tissues. Mol. Immunol. 37, 563-569. doi: 10.1016/S0161-5890(00)00084-5

Dimopoulos, G., Christophides, G. K., Meister, S., Schultz, J., White, K. P., Barillas-Mury, C., et al. (2002). Genome expression analysis of Anopheles gambiae: responses to injury, bacterial challenge, and malaria infection. Proc. Natl. Acad. Sci. U.S.A. 99, 8814-8819. doi: 10.1073/pnas.0922 74999

Dimopoulos, G., Seeley, D., Wolf, A., and Kafatos, F. C. (1998). Malaria infection of the mosquito Anopheles gambiae activates immune-responsive genes during critical transition stages of the parasite life cycle. EMBO J. 17, 6115-6123. doi: 10.1093/emboj/17.21.6115

Dolezelova, E., Nothacker, H-P., Civelli, O., Bryant, P. J., and Zurovec, M. (2007). A Drosophila adenosine receptor activates cAMP and calcium signaling. Insect Biochem. Mol. Biol. 37, 318-329. doi: 10.1016/j.ibmb.2006. 12.003

Du Pasquier, L., and Flajnik, M. (1999). "Origin and evolution of the vertebrate immune system," in Fundamental Immunology, ed. W. E. Paul (Philadelphia: Lippincott Williams \& Wilkins), 605-650.

Ferguson, H. M., and Read, A. F. (2002). Why is the effect of malaria parasites on mosquito survival still unresolved? Trends Parasitol. 18, 256-261. doi: 10.1016/S1471-4922(02)02281-X

Foley, D. (1978). "Innate cellular defense by mosquito hemocytes," in Invertebrate Models for Biomedical Research, eds L. Bulla, Jr. and T. Cheng. (New York: Springer), 113-144.

Foley, E., and O'Farrell, P. H. (2003). Nitric oxide contributes to induction of innate immune responses to gram-negative bacteria in Drosophila. Genes Dev. 17, 115-125. doi: 10.1101/gad.1018503

Forst, C. V. (2006). Host-pathogen systems biology. Drug Discov. Today 11, 220-227. doi: 10.1016/S1359-6446(05)03735-9

Fountain, S., and Burnstock, G. (2009). An evolutionary history of P2X receptors. Purinergic Signal. 5, 269-272. doi: 10.1007/s11302-008-9127-x

Friend, W. G., and Smith, J. J. B. (1977). Factors affecting feeding by bloodsucking insects. Annu. Rev. Entomol. 22, 309-331. doi: 10.1146/annurev.en.22.010177.001521

Gallucci, S., and Matzinger, P. (2001). Danger signals: SOS to the immune system. Curr. Opin. Immunol. 13, 114-119. doi: 10.1016/S0952-7915(00) 00191-6

Gloire, G., Legrand-Poels, S., and Piette, J. (2006). NF-кB activation by reactive oxygen species: fifteen years later. Biochem. Pharmacol. 72, 1493-1505. doi: 10.1016/j.bcp.2006.04.011

Gooding, R. H. (1973). The digestive processes of haematophagous insects: IV. Secretion of trypsin by Aedes aegypti (Diptera: Culicidae). Can. Entomol. 105, 599-603. doi: 10.4039/Ent105599-4

Grieco, J. P., Achee, N. L., Briceno, I., King, R., Andre, R., Roberts, D., et al. (2003). Comparison of life table attributes from newly established colonies of Anopheles albimanus and Anopheles vestitipennis in northern Belize. J. Vector Ecol. 28, 200-207.

Han, Y. S., Thompson, J., Kafatos, F. C., and Barillas-Mury, C. (2000). Molecular interactions between Anopheles stephensi midgut cells and Plasmodium berghei: the time bomb theory of ookinete invasion of mosquitoes. EMBO J. 19, 60306040. doi: 10.1093/emboj/19.22.6030

Harvey, W., and Blankemeyer, J. (1975). "Epithelial structure and function," in Invertebrate Immunity. Mechanisms of Invertebrate Vector-Parasite Relations, eds K. Matamorosch and R. Shope (New York: Academic Press), 3-23.

Hecker, H. (1977). Structure and function of midgut epithelial cells in culicidae mosquitoes (Insecta, Diptera). Cell Tissue Res. 184, 321-341. doi: 10.1007/BF00219894

Heil, M. (2012). Damaged-self recognition as a general strategy for injury detection. Plant Signal. Behav. 7, 576-580. doi: 10.4161/psb.19921

Herrera-Ortíz, A., Lanz-Mendoza, H., Martínez-Barnetche, J., Hernández-Martínez, S., Villarreal-Treviño, C., Aguilar-Marcelino, L., et al. (2004). Plasmodium berghei ookinetes induce nitric oxide production in Anopheles pseudopunctipennis midguts cultured in vitro. Insect Biochem. Mol. Biol. 34, 893-901. doi: 10.1016/j.ibmb.2004.05.007 
Hernández-Martínez, S., Lanz-Mendoza, H., Martínez-Barnetche, J., and Rodríguez, M. (2013). Antimicrobial properties of Anopheles albimanus pericardial cells. Cell Tissue Res. 351, 127-137. doi: 10.1007/s00441-012-1505-1506

Hernández-Martínez, S., Lanz-Mendoza, H., Rodrguez, M. H., González-Ceron, L., and Tsutsumi, V. (2002). Cellular-mediated reactions to foreign organisms inoculated into the hemocoel of Anopheles albimanus (Diptera: Culicidae). J Med. Entomol. 39, 61-69. doi: 10.1603/0022-2585-39.1.61

Herrera-Ortiz, A., Martínez-Barnetche, J., Smit, N., Rodriguez, M. H., and Lanz-Mendoza, H. (2011). The effect of nitric oxide and hydrogen peroxide in the activation of the systemic immune response of Anopheles albimanus infected with Plasmodium berghei. Dev. Comp. Immunol. 35, 44-50. doi: 10.1016/j.dci.2010.08.004

Hillyer, J. F., Barreau, C., and Vernick, K. D. (2007). Efficiency of salivary gland invasion by malaria sporozoites is controlled by rapid sporozoite destruction in the mosquito haemocoel. Int. J. Parasitol. 37, 673-681. doi: 10.1016/j.ijpara.2006.12.007

Hillyer, J. F., Schmidt, S. L., and Christensen, B. M. (2003). Rapid phagocytosis and melanization of bacteria and Plasmodium sporozoites by hemocytes of the mosquito Aedes aegypti. J. Parasitol. 89, 62-69. doi: 10.1645/00223395(2003)089[0062:RPAMOB]2.0.CO;2

Hirschhorn, R., and Candotti, F. (2007). "Immunodeficiency due to defects of purine metabolism," in Primary Immunodeficiency Diseases: A Molecular and Genetic Approach, 2nd Edn, eds H. D. Hans, D. Ochs, E. Smith, and J. M. Puck (Oxford: Oxford University Press), 169-196.

Hoffmann, J., Kafatos, F., Janeway, C., and Ezekowitz, R. (1999). Phylogenetic perspectives in innate immunity. Science 284, 1313-1318. doi: 10.1126/science.284.5418.1313

Hurd, H., Grant, K. M., and Arambage, S. C. (2006). Apoptosis-like death as a feature of malaria infection in mosquitoes. Parasitology 132, S33-S47. doi: $10.1017 /$ S0031182006000849

Hurd, H., Taylor, P. J., Adams, D., Underhill, A., Eggleston, P., and Koella, J. (2005). Evaluating the costs of mosquito resistance to malaria parasites. Evolution 59, 2560-2572. doi: 10.1554/05-211.1

Imamura, M., Yang, J., and Yamakawa, M. (2002). cDNA cloning, characterization and gene expression of nitric oxide synthase from the silkworm, Bombyx mori Insect Mol. Biol. 11, 257-265. doi: 10.1046/j.1365-2583.2002.00333.x

Ivison, S. M., Himmel, M. E., Mayer, M., Yao, Y., Kifayet, A., Levings, M. K. et al. (2011). The stress signal extracellular ATP modulates antiflagellin immune responses in intestinal epithelial cells. Inflamm. Bowel Dis. 17, 319-333. doi: 10.1002/ibd.21428

King, J., and Hillyer, J. (2013). Spatial and temporal in vivo analysis of circulating and sessile immune cells in mosquitoes: hemocyte mitosis following infection. BMC Biol. 11:55. doi: 10.1186/1741-7007-11-55

King, J. G., and Hillyer, J. F. (2012). Infection-induced interaction between the mosquito circulatory and immune systems. PLoS Pathog. 8:e1003058. doi: 10.1371/journal.ppat.1003058

Klein, J. (1999). Self-nonself discrimination, histoincompatibility, and the concept of immunology. Immunogenetics 50, 116-123. doi: 10.1007/s002510050587

Klowden, M. J. (2008). Physiological Systems in Insects. San Diego, CA: Academic Press.

Koropatnick, T. A., Engle, J. T., Apicella, M. A., Stabb, E. V., Goldman, W. E., and McFall-Ngai, M. J. (2004). Microbial factor-mediated development in a hostbacterial mutualism. Science 306, 1186-1188. doi: 10.1126/science.1102218

Kumar, S., and Barillas-Mury, C. (2005). Ookinete-induced midgut peroxidases detonate the time bomb in anopheline mosquitoes. Insect Biochem. Mol. Biol. 35, 721-727. doi: 10.1016/j.ibmb.2005.02.014

Kumar, S., Christophides, G. K., Cantera, R., Charles, B., Han, Y. S., Meister, S., et al (2003). The role of reactive oxygen species on Plasmodium melanotic encapsulation in Anopheles gambiae. Proc. Natl. Acad. Sci. U.S.A. 100, 14139-14144. doi: 10.1073/pnas.2036262100

Kumar, S., Gupta, L., Han, Y. S., and Barillas-Mury, C. (2004). Inducible peroxidases mediate nitration of Anopheles midgut cells undergoing apoptosis in response to Plasmodium invasion. J. Biol. Chem. 279, 53475-53482. doi: 10.1074/jbc.M409905200

Kurtz, J. (2005). Specific memory within innate immune systems. Trends Immunol. 26, 186-192. doi: 10.1016/j.it.2005.02.001

Lackie, A. M. (1988). "Haemocyte behaviour," in Advances in Insect Physiology, eds P. D. Evans and V. B. Wigglesworth (San Diego, CA: Academic Press), 85-178.
Lanz-Mendoza, H., Hernández-Martínez, S., Ku-López, M., Rodríguez, M. D. C., Herrera-Ortiz, A., and Rodríguez, M. H. (2002). Superoxide anion in Anopheles albimanus hemolymph and midgut is toxic to Plasmodium berghei ookinetes. J. Parasitol. 88, 702-706. doi: 10.1645/00223395(2002)088[0702:SAIAAH]2.0.CO;2

Lazzaro, B. P., and Rolff, J. (2011). Danger, microbes, and homeostasis. Science 332, 43-44. doi: 10.1126/science.1200486

Litman, G. W., and Cooper, M. D. (2007). Why study the evolution of immunity? Nat. Immunol. 8, 547-548. doi: 10.1038/ni0607-547

Little, T. J., Hultmark, D., and Read, A. F. (2005). Invertebrate immunity and the limits of mechanistic immunology. Nat. Immunol. 6, 651-654. doi: $10.1038 /$ ni1219

Little, T. J., and Kraaijeveld, A. R. (2004). Ecological and evolutionary implications of immunological priming in invertebrates. Trends Ecol. Evol. 19, 58-60. doi: 10.1016/j.tree.2003.11.011

Little, T. J., O’Connor, B., Colegrave, N., Watt, K., and Read, A. F. (2003). Maternal transfer of strain-specific immunity in an invertebrate. Curr. Biol. 13, 489-492. doi: 10.1016/S0960-9822(03)00163-5

Luckhart, S., Crampton, A. L., Zamora, R., Lieber, M. J., Dos Santos, P. C., Peterson, T. M. L., et al. (2003). Mammalian transforming growth factor $\beta 1$ activated after ingestion by Anopheles stephensi modulates mosquito immunity. Infect. Immun. 71, 3000-3009. doi: 10.1128/IAI.71.6.3000-3009.2003

Luckhart, S., and Li, K. (2001). Transcriptional complexity of the Anopheles stephensi nitric oxide synthase gene. Insect Biochem. Mol. Biol. 31, 249-256. doi: 10.1016/S0965-1748(00)00144-2

Luckhart, S., and Rosenberg, R. (1999). Gene structure and polymorphism of an invertebrate nitric oxide synthase gene. Gene 232, 25-34. doi: 10.1016/S03781119(99)00121-3

Luckhart, S., Vodovotz, Y., Cui, L., and Rosenberg, R. (1998). The mosquito Anopheles stephensi limits malaria parasite development with inducible synthesis of nitric oxide. Proc. Natl. Acad. Sci. U.S.A. 95, 5700-5705. doi: 10.1073/pnas.95.10.5700

Maier, S., Galellis, J., and McDermid, H. (2005). Phylogenetic analysis reveals a novel protein family closely related to adenosine deaminase. J. Mol. Evol. 61, 776-794. doi: 10.1007/s00239-005-0046-y

Maier, W. A., Becker-Feldman, H., and Seitz, H. M. (1987). Pathology of malaria-infected mosquitoes. Parasitol. Today 3, 216-218. doi: 10.1016/01694758(87)90063-9

Márkus, R., Kurucz, É., Rus, F., and Andó, I. (2005). Sterile wounding is a minimal and sufficient trigger for a cellular immune response in Drosophila melanogaster. Immunol. Lett. 101, 108-111. doi: 10.1016/j.imlet.2005.03.021

Marois, E. (2011). The multifaceted mosquito anti-Plasmodium response. Curr. Opin. Microbiol. 14, 429-435. doi: 10.1016/j.mib.2011.07.016

Martinez-Barnetche, J., Gomez-Barreto, R., Ovilla-Munoz, M., Tellez-Sosa, J., Lopez, D. E., Dinglasan, R., et al. (2012). Transcriptome of the adult female malaria mosquito vector Anopheles albimanus. BMC Genomics 13:207. doi: 10.1186/1471-2164-13-207

Matthews, H., Ali, M., Carter, V., Underhill, A., Hunt, J., Szor, H., et al. (2012). Variation in apoptosis mechanisms employed by malaria parasites: the roles of inducers, dose dependence and parasite stages. Malar. J. 11, 297. doi: 10.1186/1475-2875-11-297

Matuschewski, K. (2006). Getting infectious: formation and maturation of Plasmodium sporozoites in the Anopheles vector. Cell Microbiol. 8, 1547-1556. doi: 10.1111/j.1462-5822.2006.00778.x

Matzinger, P. (1994). Tolerance, danger, and the extended family. Annu. Rev Immunol. 12, 991-1045. doi: 10.1146/annurev.iy.12.040194.005015

Matzinger, P., and Kamala, T. (2011). Tissue-based class control: the other side of tolerance. Nat. Rev. Immunol. 11, 221-230. doi: 10.1038/nri2940

Medzhitov, R., and Janeway, C. A. (2002). Decoding the patterns of self and nonself by the innate immune system. Science 296, 298-300. doi: 10.1126/science.1068883

Medzhitov, R., Schneider, D. S., and Soares, M. P. (2012). Disease tolerance as a defense strategy. Science 335, 936-941. doi: 10.1126/science. 1214935

Meis, J. F. G. M., Wismans, P. G. P., Jap, P. H. K., Lensen, A. H. W., and Ponnudurai, T. (1992). A scanning electron microscopic study of the sporogonic development of Plasmodium falciparum in Anopheles stephensi. Acta Trop. 50, 227-236. doi: 10.1016/0001-706X(92)90079-D

Mercurio, F., and Manning, M. (1999). NF-kB as a primary regulator of the stress response. Oncogene 18,6163-6171. doi: 10.1038/sj.onc. 1203174 
Metchnikoff, E. (1893). Lectures on the Comparative Pathology of Inflammation. London: Kegan Paul.

Meyer-Fernandes, J. R., Lanz-Mendoza, H., Gondim, K. C., Willott, E., and Wells, M. A. (2000). Ectonucleotide diphosphohydrolase activities in hemocytes of larval Manduca sexta. Arch. Biochem. Biophys. 382, 152-159. doi: 10.1006/abbi.2000.1980

Molina-Cruz, A., Garver, L. S., Alabaster, A., Bangiolo, L., Haile, A., Winikor, J., et al. (2013). The human malaria parasite PFS47 gene mediates evasion of the mosquito immune system. Science 340, 984-987. doi: 10.1126/science. 1235264

Moreno-García, M., Condé, R., Bello-Bedoy, R., and Lanz-Mendoza, H. (2014). The damage threshold hypothesis and the immune strategies of insects. Infect. Genet. Evol. 24, 25-33. doi: 10.1016/j.meegid.2014.02.010

Moret, Y. (2006). 'Trans-generational immune priming': specific enhancement of the antimicrobial immune response in the mealworm beetle, Tenebrio molitor Proc. R. Soc. B Biol. Sci. 273, 1399-1405. doi: 10.1098/rspb.2006.3465

Mueller, A-K., Kohlhepp, F., Hammerschmidt, C., and Michel, K. (2010). Invasion of mosquito salivary glands by malaria parasites: prerequisites and defense strategies. Int. J. Parasitol. 40, 1229-1235. doi: 10.1016/j.ijpara.2010.05.005

Mutai, B., and Waitumbi, J. (2010). Apoptosis stalks Plasmodium falciparum maintained in continuous culture condition. Malar. J. 9(suppl. 3):S6. doi: 10.1186/1475-2875-9-S3-S6

Nacer, A., Walker, K., and Hurd, H. (2008). Localisation of laminin within Plasmodium berghei oocysts and the midgut epithelial cells of Anopheles stephensi. Parasites Vectors 1, 33. doi: 10.1186/1756-3305-1-33

Nam, H-J., Jang, I-H., You, H., Lee, K-A., and Lee, W-J. (2012). Genetic evidence of a redox-dependent systemic wound response via Hayan protease-phenoloxidase system in Drosophila. EMBO J. 31, 1253-1265. doi: 10.1038/emboj.2011.476

Nappi, A., Vass, E., Frey, F., and Carton, Y. (1995). Superoxide anion generation in Drosophila during melanotic encapsulation of parasite. Eur. J. Cell Biol. 68, 450-456.

Nappi, A. J., and Vass, E. (1993). Melanogenesis and the generation of cytotoxic molecules during insect cellular immune reactions. Pigment. Cell Res. 6, 117-126. doi: 10.1111/j.1600-0749.1993.tb00590.x

Nappi, A. J., and Vass, E. (1998). Hydrogen peroxide production in immune-reactive Drosophila melanogaster. J. Parasitol. 84, 1150-1157. doi: 10.2307/3284664

Nappi, A. J., Vass, E., Frey, F., and Carton, Y. (2000). Nitric oxide involvement in Drosophila immunity. Nitric Oxide 4, 423-430. doi: 10.1006/niox.2000.0294

Natori, S. (1998). "Relation between insect defense proteins and development of the flesh fly, Sarcophaga peregrina," in Molecular Mechanisms of Immune Responses in Insects, eds P. T. Brey and D. Hultmark (London, UK: Chapman \& Hall Ltd) 245-260.

Nayar, J. K., and Knight, J. W. (1995). Wounding increases intracellular encapsulation (melanization) of developing Brugia malayi (Nematoda: Filarioidea) larvae in thoracic muscles of Anopheles quadrimaculatus. Comp. Biochem. Physiol. A Physiol. 112, 553-557. doi: 10.1016/0300-9629(95)02027-6

Noble, A. (2009). Do we have memory of danger as well as antigen? Trends Immunol. 30, 150-156. doi: 10.1016/j.it.2009.02.001

Novakova, M., and Dolezal, T. (2011). Expression of Drosophila adenosine deaminase in immune cells during inflammatory response. PLOS ONE 6:e17741. doi: 10.1371/journal.pone.0017741

Oliveira, G. D. A., Lieberman, J., and Barillas-Mury, C. (2012). Epithelial nitration by a peroxidase/NOX 5 system mediates mosquito antiplasmodial immunity. Science 335, 856-859. doi: 10.1126/science. 1209678

Pastor-Pareja, J., Wu, M., and Xu, T. (2008). An innate immune response of blood cells to tumors and tissue damage in Drosophila. Dis. Models Mech. 1, 144-154. doi: $10.1242 / \mathrm{dmm} .000950$

Peterson, T. M. L., Gow, A. J., and Luckhart, S. (2007). Nitric oxide metabolites induced in Anopheles stephensi control malaria parasite infection. Free Radic. Biol. Med. 42, 132-142. doi: 10.1016/j.freeradbiomed.2006.10.037

Pham, L. N., and Schneider, D. S. (2008). "Evidence for specificity and memory in the insect innate immune response," in Insect Immunology, ed. N. E. Beckage (San Diego: Academic Press), 97-127.

Philip, N., and Waters, A. P. (2013). Unveiling the malaria parasite's cloak of invisibility? Science 340, 936-937. doi: 10.1126/science.1239146

Pinto, S. B., Kafatos, F. C., and Michel, K. (2008). The parasite invasion marker SRPN6 reduces sporozoite numbers in salivary glands of Anopheles gambiae. Cell Microbiol. 10, 891-898. doi: 10.1111/j.1462-5822.2007.01091.x
Pollitt, L., Colegrave, N., Khan, S., Sajid, M., and Reece, S. (2010). Investigating the evolution of apoptosis in malaria parasites: the importance of ecology. Parasit. Vectors 3, 105. doi: 10.1186/1756-3305-3-105

Ramirez, J. L., Garver, L. S., Brayner, F. A., Alves, L. C., Rodrigues, J., Molina-Cruz, A., et al. (2014). The role of hemocytes in Anopheles gambiae antiplasmodial immunity. J. Innate Immun. 6, 119-128. doi: 10.1159/000353765

Rivkin, H., Kroemer, J. A., Bronshtein, A., Belausov, E., Webb, B. A., and Chejanovsky, N. (2006). Response of immunocompetent and immunosuppressed Spodoptera littoralis larvae to baculovirus infection. J. Gen. Virol. 87, 2217-2225. doi: 10.1099/vir.0.81918-81910

Rizki, R. M., and Rizki, T. M. (1980). Hemocyte response to implanted tissues in Drosophila melanogaster larvae. Wilhem Roux's Arch. 189, 207-213. doi: 10.1007/BF00868679

Rodrigues, J., Brayner, F. A., Alves, L. C., Dixit, R., and Barillas-Mury, C. (2010). Hemocyte differentiation mediates innate immune memory in Anopheles gambiae mosquitoes. Science 329, 1353-1355. doi: 10.1126/science. 1190689

Rodriguez, M. H., and Hernández-Hernández, F. D. L. C. (2004). Insect-malaria parasites interactions: the salivary gland. Insect Biochem. Mol. Biol. 34, 615-624. doi: 10.1016/j.ibmb.2004.03.014

Rosenberg, R., and Rungsiwongse, J. (1991). The number of sporozoites produced by individual malaria oocysts. Am. J. Trop. Med. Hyg. 45, 574-577.

Ross, R. (1902). Researches on malaria. Nobel Lect. 25-116.

Rossignol, P. A., Ribeiro, J. M. C., and Spielman, A. (1984). Increased intradermal probing time in sporozoite-infected mosquitoes. Am. J. Trop. Med. Hyg. 33, 17-20.

Rutault, K., Alderman, C., Chain, B. M., and Katz, D. R. (1999). Reactive oxygen species activate human peripheral blood dendritic cells. Free Radic. Biol. Med. 26, 232-238. doi: 10.1016/S0891-5849(98)00194-4

Salt, G. (1970). The Cellular Reactions of Insects. Cambridge, UK: Cambridge University Press. doi: 10.1017/CBO9780511721960

Sanders, H. R., Foy, B. D., Evans, A. M., Ross, L. S., Beaty, B. J., Olson, K. E., et al. (2005). Sindbis virus induces transport processes and alters expression of innate immunity pathway genes in the midgut of the disease vector, Aedes aegypti. Insect Biochem. Mol. Biol. 35, 1293-1307. doi: 10.1016/j.ibmb.2005.07.006

Serrano-Pinto, V., Acosta-Pérez, M., Luviano-Bazán, D., Hurtado-Sil, G., Batista, C. V. F., Martínez-Barnetche, J., et al. (2010). Differential expression of proteins in the midgut of Anopheles albimanus infected with Plasmodium berghei. Insect Biochem. Mol. Biol. 40, 752-758. doi: 10.1016/j.ibmb.2010.07.011

Sinden, R., Dawes, E. J., Alavi, Y., Waldock, J., Finney, O., Mendoza, J., et al. (2007). Progression of Plasmodium berghei through Anopheles stephensi is density-dependent. PLoS Pathog. 3:e195. doi: 10.1371/journal.ppat. 0030195

Sinden, R. E. (1974). Excystment by sporozoites of malaria parasites. Nature 252, 314-314. doi: 10.1038/252314a0

Sinden, R. E., and Billingsley, P. F. (2001). Plasmodium invasion of mosquito cells: hawk or dove? Trends Parasitol. 17, 209-211. doi: 10.1016/S1471-4922(01) 01928-6

Sinden, R. E., and Strong, K. (1978). An ultrastructural study of the sporogonic development of Plasmodium falciparum in Anopheles gambiae. Trans. R. Soc. Trop. Med. Hygiene 72, 477-491. doi: 10.1016/0035-9203(78)9016790160

Sitkovsky, M. V., and Ohta, A. (2005). The 'danger' sensors that STOP the immune response: the A2 adenosine receptors? Trends Immunol. 26, 299-304. doi: 10.1016/j.it.2005.04.004

Smith, R. C., and Jacobs-Lorena, M. (2010). "Plasmodium-mosquito interactions: a tale of roadblocks and detours," in Advances in Insect Physiology, ed. J. S. Stephen (Academic Press), 119-149.

Sun, S-C., and Faye, I. (1995). Transcription of immune genes in the giant silkmoth, Hyalophora cecropia, is augmented by $\mathrm{H}_{2} \mathrm{O}_{2}$ and diminished by thiol reagents. Eur. J. Biochem. 231, 93-98. doi: 10.1111/j.1432-1033.1995. 0093f.x

Tanada, Y., and Kaya, H. K. (1993). Insect Pathology. San Diego: Academic Press.

Tidbury, H. J., Pedersen, A. B., and Boots, M. (2011). Within and transgenerational immune priming in an insect to a DNA virus. Proc. R. Soc. B Biol. Sci. 278, 871-876. doi: 10.1098/rspb.2010.1517

Trautmann, A. (2009). Extracellular ATP in the immune system: more than just a “danger signal". Sci. Signal. 2, pe6. doi: 10.1126/scisignal.256pe6 
Tripet, F., Aboagye-Antwi, F., and Hurd, H. (2008). Ecological immunology of mosquito-malaria interactions. Trends Parasitol. 24, 219-227. doi: 10.1016/j.pt.2008.02.008

Virchow, R. L. K. (1863). Cellular Pathology as Based Upon Physiological and Pathological Histology.../by Rudolf Virchow. Translated from the 2nd edition of the original by Frank Chance. With notes and numerous emendations, principally from MS. Notes of the author. Philadelphia: J. B. Lippincott.

Vlachou, D., Schlegelmilch, T., Runn, E., Mendes, A., and Kafatos, F. C. (2006). The developmental migration of Plasmodium in mosquitoes. Curr. Opin. Genet. Dev. 16, 384-391. doi: 10.1016/j.gde.2006.06.012

Vlachou, D., Zimmermann, T., Cantera, R., Janse, C. J., Waters, A. P., and Kafatos, F. C. (2004). Real-time, in vivo analysis of malaria ookinete locomotion and mosquito midgut invasion. Cell Microbiol. 6, 671-685. doi: 10.1111/j.1462-5822.2004.00394.X

Vodovotz, Y. (2006). Deciphering the complexity of acute inflammation using mathematical models. Immunol. Res. 36, 237-245. doi: 10.1385/IR:36:1,237

Wallach, D., Kang, T-B., and Kovalenko, A. (2014). Concepts of tissue injury and cell death in inflammation: a historical perspective. Nat. Rev. Immunol. 14, 51-59. doi: 10.1038/nri3561

Warburg, A., Shtern, A., Cohen, N., and Dahan, N. (2007). Laminin and a Plasmodium ookinete surface protein inhibit melanotic encapsulation of Sephadex beads in the hemocoel of mosquitoes. Microbes Infect. 9, 192-199. doi: 10.1016/j.micinf.2006.11.006

Whitten, M. M. A., Shiao, S. H., and Levashina, E. A. (2006). Mosquito midguts and malaria: cell biology, compartmentalization and immunology. Parasite Immunol. 28, 121-130. doi: 10.1111/j.1365-3024.2006.00804.x

Yurchenco, P. D., and O’Rear, J. (1993). "Supramolecular organization of basement membranes," in Molecular and Cellular Aspects of Basement Membrane, eds D. H. Rohrbach and R. Timpl (New York: Academic Press), 19-47.
Zeiser, R., Penack, O., Holler, E., and Idzko, M. (2011). Danger signals activating innate immunity in graft-versus-host disease. J. Mol. Med. 89, 833-845. doi: 10.1007/s00109-011-0767-x

Zieler, H., and Dvorak, J. A. (2000). Invasion in vitro of mosquito midgut cells by the malaria parasite proceeds by a conserved mechanism and results in death of the invaded midgut cells. Proc. Natl. Acad. Sci. U.S.A. 97, 11516-11521. doi: 10.1073/pnas.97.21.11516

Zurovec, M., Dolezal, T., Gazi, M., Pavlova, E., and Bryant, P. J. (2002). Adenosine deaminase-related growth factors stimulate cell proliferation in Drosophila by depleting extracellular adenosine. Proc. Natl. Acad. Sci. U.S.A. 99, 4403-4408. doi: 10.1073/pnas.062059699

Conflict of Interest Statement: The authors declare that the research was conducted in the absence of any commercial or financial relationships that could be construed as a potential conflict of interest.

Received: 09 July 2014; accepted: 20 August 2014; published online: 09 September 2014. Citation: Moreno-García M, Recio-Tótoro B, Claudio-Piedras F and Lanz-Mendoza H (2014) Injury and immune response: applying the danger theory to mosquitoes. Front. Plant Sci. 5:451. doi: 10.3389/fpls.2014.00451

This article was submitted to Plant-Microbe Interaction, a section of the journal Frontiers in Plant Science.

Copyright (C) 2014 Moreno-García, Recio-Tótoro, Claudio-Piedras and Lanz-Mendoza. This is an open-access article distributed under the terms of the Creative Commons Attribution License (CC BY). The use, distribution or reproduction in other forums is permitted, provided the original author(s) or licensor are credited and that the original publication in this journal is cited, in accordance with accepted academic practice. No use, distribution or reproduction is permitted which does not comply with these terms. 